\title{
The Experimental Study of Heating System with the Prefabricated Solar Heat Collection Plates

\author{
Zhi-Guo DUAN ${ }^{1}$, Li-Quan YANG ${ }^{2}$, a*, Qi WANG ${ }^{2}$, b, Bo-Wen $\mathrm{LI}^{1}$, Xue ZHAO', \\ Miao $\mathrm{YU}^{1}$
} \\ ${ }^{1}$ TaiYang new energy of technology co., LTD, Changchun, China \\ ${ }^{2}$ College of engineering and technology, Jilin Agricultural University Changchun, Jilin, China \\ a1002942505@qq.com, b2503468901@qq.com \\ ${ }^{*}$ Corresponding author
}

Keywords: Prefabricated solar heat collection plates, heating system, Heat collection efficiency.

\begin{abstract}
Designed a kind of prefabricated solar heating system, It tested the performance of the heating system. The heating system mainly includes prefabricated solar heat collection plates, blower, gas transmission pipeline, heat accumulator, bulk flow device, control box. The solar heating system can be effective supplied for houses. Excess heat is stored in the storage device. The excess heat Provide the night to use, So as to achieve the goal of 24 hours of heating. The test results show that the heat efficiency of the heat collection plate is up to $76 \%$, the average thermal efficiency of the system is $28 \%$. The heating room temperature is 10 centigrade than environment temperature. When the variation of solar radiation is not large, the heat collection efficiency of the system is greatly influenced by the temperature of inlet and outlet.
\end{abstract}

\section{Introduction}

Solar energy is a kind of new energy, it is widely distributed; non-pollution. It is doesn't produce any waste, solar energy is an ideal clean energy. The heating system with prefabricated solar heat collection plates is applied to the roof of building; it supplied heating for the cold area in winter. Excess heat is stored in the storage device during the day time. The excess heat provides the night to use. So as to achieve the goal of 24 hours of heating. The heating system is used in factories; workshops and schools. In this paper, it mainly designed the structure of heating system and the performance test, it provided theory and reference datas for the practical application of solar energy heating system.

\section{System overall structure}

Heating system is a kind of using air as a heat transfer medium solar-thermal conversion system. The heating system mainly includes prefabricated solar heat collection plates,blower,gas transmission pipeline, heat accumulator,bulk flow device,control box. As shown in Figure 1 and as shown in Figure 2 of physical photo. The heating system is composed of 8 pieces of prefabricated solar heat collection plates series and parallel connection. The installation angle of the heat collecting plate is 50 degrees, in the air inlet has a forced air blower, the blower promotes the air circulation flow. 


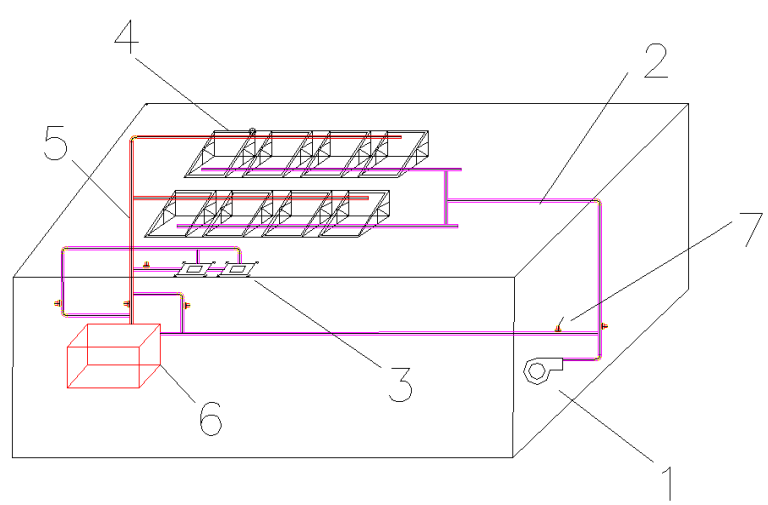

Fig.1 General structure of prefabricated solar heat collection plates 1-fan 2-ducts 3-diffuser 4-Panels 5-Hot air ducts 6-Regenerator 7-Air valve

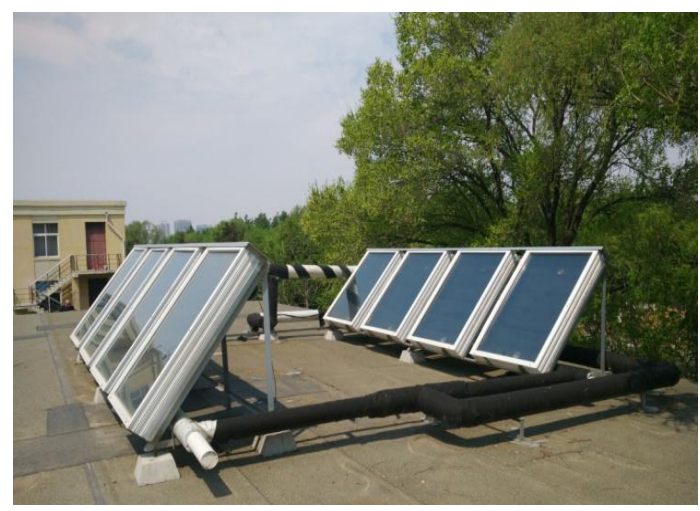

Fig.2 Photo of heating system with the prefabricated solar heat collection plates

Prefabricated solar heat collection plates basic structure as shown in figure 3. Heat collecting plate can be prefabricated. Its structure mainly consists of seven parts which are composite frame, glasses cover, absorber plates, metal mesh, insulation backplane, air inlet pipe, air outlet pipe. A double ordinary glass cover was installed in a double-layer steel type material superposed composite frame. It can reduce the heat loss . The corrugated penetrated metal mesh which direction was vertical to airflow been filled between glasses and absorber plates[5] for increasing solar radiation absorption area and strengthening heat transfer between air and absorber body[3] . The corrugated angle of metal screen is 90 DEG. They could improve the thermal efficiency. The coating is simple, the material price is reasonable, and it has some aesthetics. Absorber plate painted absorber paint coat for absorbing solar energy and transforming into hot as much as possible.

The control system can automatically control the air flow, it realized the function of the main performance parameters of the automatic display output, it tested system of temperature; wind speed; Light illumination; etc. The thermal performance testing was exported (show in figure4).

The heat accumulator mainly consists of seven parts which are air outlet; net; air inlet; Heat storage block; Frame; Insulation board; shell etc. The heat storage materials were made of a percentage of phase change materials; light aggregate; cement; admixture, it was made of square shape, they were placed in a separate online wire. The hot air enters heat accumulator from air inlet, through the heat storage material, the heat is stored in the heat storage block. The stored heat is delivered to the room through the air blower at night (shown in figure5). 

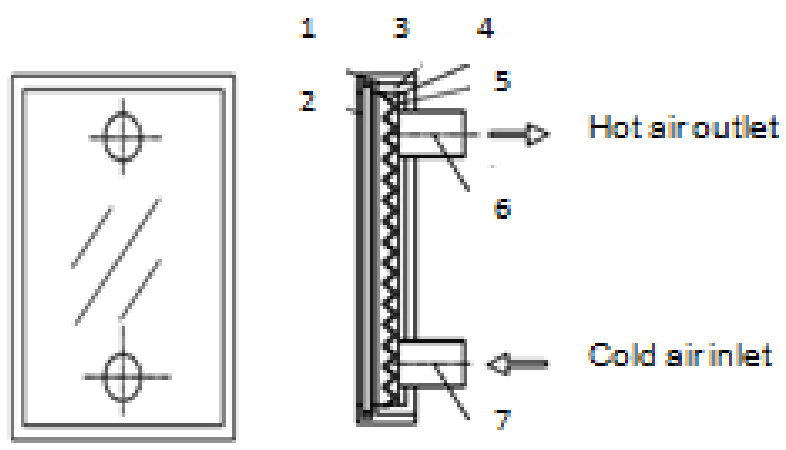

Fig.3 The structure of the collector panels

1-Composite frame 2-Glass cover 3-Absorber plate 4-V type of metal mesh 5- Insulation backplane 6-Hot air outlet 7Cold air inlet

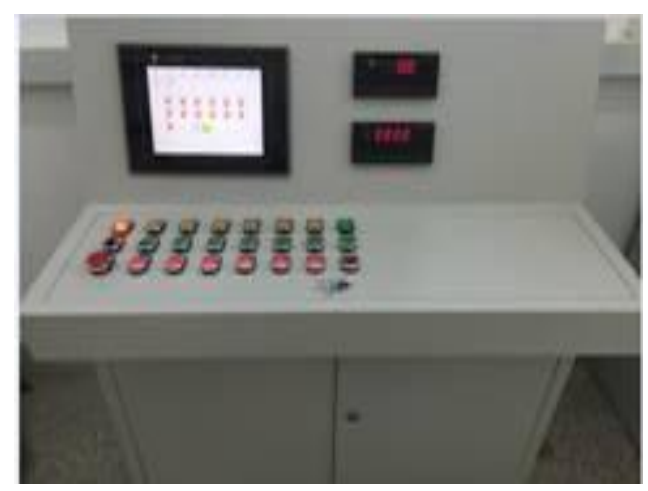

Fig.4 Control box

\section{Thermal performance testing}

Test Conditions and Test Instrument. The test of time is two consecutive days of sunny weather; the period of time is from 9:30 to 15:30 in 2016, May 9, 10 days. During the test, transparent lighting surface of heat collection plate can't be shaded by the outside world, The average temperature of the environment is in the range of $15 \sim 30$ degree, The wind speed of the external environment is between $2.5 \mathrm{~m} / \mathrm{s}$ and $4 \mathrm{~m} / \mathrm{s}$. It recorded all data every 30 minutes. It recorded the system inlet temperature and outlet temperature of the solar heat collection plate heating system in every 30 minutes ${ }^{[3]}$.

This test selected a energy laboratory of Jilin Agricultural University as the test object, the size of the laboratory is $5.6 \mathrm{~m} \times 2.4 \mathrm{~m} \times 4.8 \mathrm{~m}$. The heating area of the laboratory is $14 \mathrm{~m}^{2}$, the walls were used solid brick which the thickness was $240 \mathrm{~mm}$, the windows were a double layer vacuum glass with excellent thermal insulation performance. Temperature sensors were used to measure the system inlet, the system exit, the temperature of the inlet and outlet of a single heat collector, and the temperature of the measured room .Using JY-GD2 pipeline wind speed meter measured the flow rate at the outlet of the system, recording the solar radiation intensity with the TBQ-2 type radiation meter. The test range is w/m2 0-2000w/m2 (shown in Figure 6). 


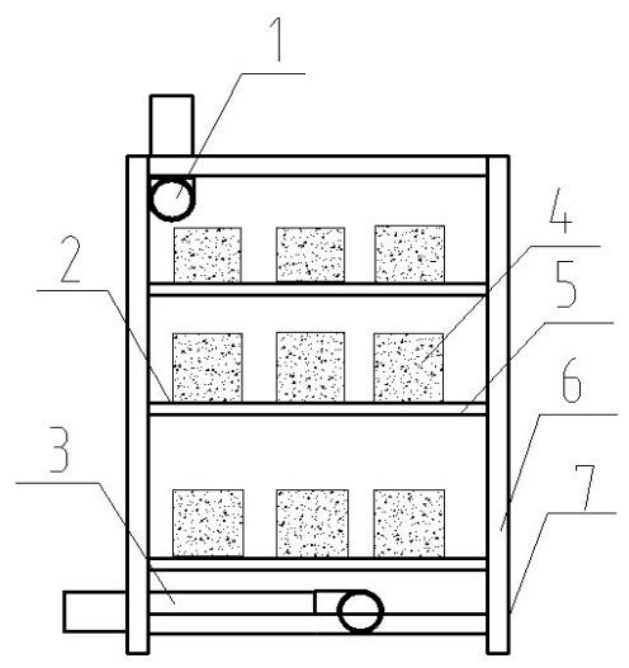

Fig.5 Heat accumulator

1- air outlet 2-net 3-air inlet 4- Heat storage block 5-Frame 6-Insulation board 7-shell

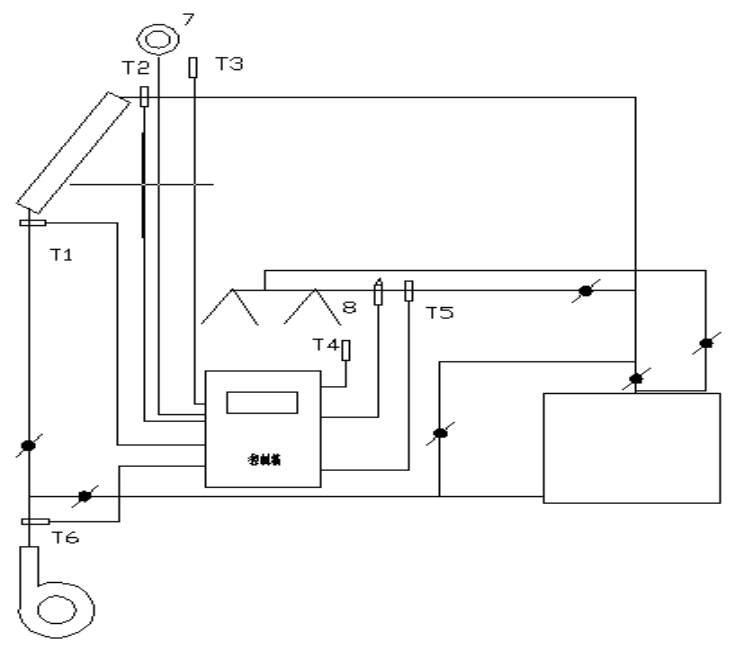

Fig.6 Measuring point distribution of solar heating system

Test Results and Analysis. Through 2 consecutive days with 2 times of testing. The solar radiation intensity and the temperature curve of the solar heating system are shown in Figure 7. The heat collection efficiency of a single heat collector and the heat collection efficiency of the system were determined. By using the formula of heat collection efficiency:

$$
\eta=\frac{m c_{p}\left(t_{o}-t_{i}\right)}{A I}
$$

Type: $\mathrm{m}$ - Mass flow of heated media, $\mathrm{kg} / \mathrm{s}$;

$\mathrm{Cp}$ - The heat capacity of air, $\mathrm{J} / \mathrm{kg}^{\circ} \mathrm{C}$;

ti, 一 Inlet temperature, ${ }^{\circ} \mathrm{C}$;

t0, 一 Outlet temperature, ${ }^{\circ} \mathrm{C}$ 。

After finishing the collection efficiency of the metal mesh collector plate, which obtains the Instantaneous collection thermal efficiency curve (show in Figure 8). The collector thermal efficiency through linear regression to get the instantaneous efficiency equation: $y=-12.602 x+0.9551$, The correlation coefficient is -0.90758 . The maximum heat collection efficiency is $76 \%$, The heat storage and thermal insulation performance of prefabricated solar heat collection plates is good, Its collection efficiency is higher than ordinary collectors collection efficiency, prefabricated solar heat collection plates accord with Energy-saving solar building. 
The outlet temperature of the system and the heating room temperature all reach the maximum value at 12:30, 47 centigrade and 29 centigrade. The solar radiation intensity reaches the maximum value at about 11:30, which is $1002 \mathrm{~W} / \mathrm{m} 2$, the heat collection plates and the rise of temperature of the air relative to the change of intensity of solar radiation has a certain lag. In the whole heating process, the average outlet temperature of the system is 44 centigrade; the average temperature of the heating room is 27 centigrade. The heating room temperature was around 10 centigrade higher than the environment temperature. The average thermal efficiency of the system is $28 \%$, the environmental temperature; wind speed; import and export temperature, solar radiation influenced on the system of collection efficiency. When the small variations of the solar radiation, the system of collection efficiency was greatly influenced by the temperature of import and export, under the condition of $t$ the solar radiation is higher and stable and the small wind speed test, the heat collection efficiency is less affected by the external environment.

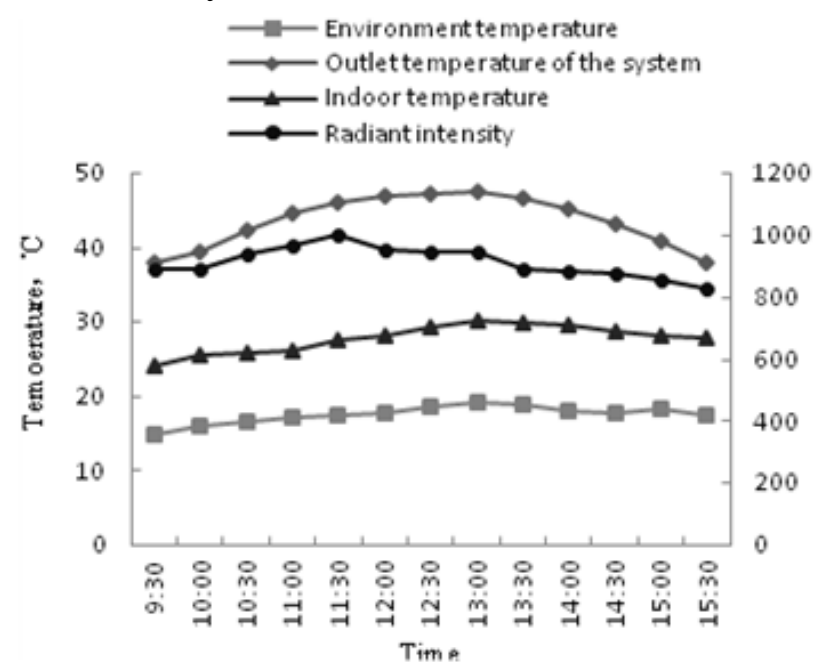

Fig.7 Real-time temperature curve of the roof solar house and solar radiation intensity

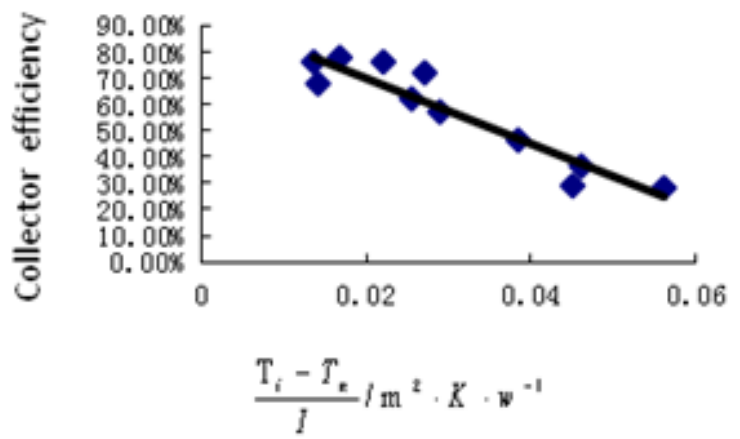

Fig.8 The transient thermal efficiency curve with metal mesh

\section{Conclusion}

Designed a kind of the heating system with prefabricated solar heat collection plates. Through to the system overall design and testing. It can obtain the solar heat collection plates that are prefabricated forming, the collection efficiency is higher, and the heat accumulator applicated of phase change composites, regenerative effect is good. The application of automatic control system is convenient and flexible. The heating room temperature was around 10 centigrade higher than the environment temperature. The average temperature of the heating room is 27 centigrade. The highest heat collection efficiency of a single heat collection plate is $76 \%$, when the small variations of the solar radiation, the system of collection efficiency were greatly influenced by the temperature of import and export. The average collector efficiency of heating system is $28 \%$. 


\section{Acknowledgments}

This study was funded by the Science and technology project of Chang Chun (14KP022), and was thanked to Jilin Agricultural University.

\section{References}

[1] Min Yan, Lin Qiu, Geng Ren, et al. Energy-saving. Vol.9 (2009), p. 12-14.In Chinese.

[2] Weijia Su, Ran Zuo ,Zhiqiang Zhang etal . Acta Energiae Solaris Sinica . VOL . 29（2008）, p .449-453. in Chinese.

[3] EckM, Steinmann WD.Modelling and Design of Direct Solar Steam Generating Collector Fields[J].Journal of Solar Energy Engineering,2005,127:371-380.

[4] Zhizhang cheng, Bin Chen, Wei Yao et al. Building Science. Vol.27 (2011), p.31-35.In Chinese.

[5] Ting Ban, Ming Zhu, Hai Wang. Transactions of the Chinese society of Agricultural Engineering. Vol . 27(2011), p.277-281. In Chinese.

[6] H. Boyer, F. Miranville, D. Bigot,Heat Transfer in Buildings: Application to Solar Air Collector and Trombe Wall Design University of La Reunion [J]. Building and Environment, 2010, 29(2) : 227-242.

[7] A.H.Abdullah,H.Z.Abou-Ziyan,A.A.Ghoneim .Thermal performance of flat plate solar collector using various arrangements of compound honeycomb[J].Energy Conversion and Management 44(2003):3093-3112.

[8] Gang Ding, Ran Zuo, Xupeng Zhang et al. Renewable Energy. Vol.29 (2011), p. 12-15. In Chinese.

[9] Gerilla GP, Teknomo K, Hokao K. An environmental assessment of wood and steel reinforced concrete housing construction [J] Building and Environment, 2007, 42(7):2778 2784 .

[10] Tae-Jin Kin, Chong-Bo Kim, Hybird Photovoltaic(PV/T)Air and Solar Collectors Suitable foBuilding Intergrated Applications American Journal of environmental Sciences [J]; 2009,5(5):618-62. 